\title{
A multicriteria model for ranking of improvement approaches in construction companies based on the PROMETHÉE 11 method
}

\author{
Renata Maciel de Melo ${ }^{a *}$, Denise Dumke de Medeiros ${ }^{b}$, Adiel Teixeira de Almeida ${ }^{c}$ \\ a*renatamaciel0@gmail.com, UFPE, Brasil \\ ${ }^{\mathrm{b}}$ medeirosdd@gmail.com, UFPE, Brasil \\ calmeidaatd@gmail.com, UFPE, Brasil
}

\begin{abstract}
The quality of the construction production process may be improved using several different methods such as lean Construction, ISO 9001, ISO 14001 or ISO 18001. Construction companies need a preliminary study and systematic implementation of changes to become more competitive and efficient. This paper presents a multicriteria decision model for the selection and ranking of such alternatives for improvement approaches regarding the aspects of quality, sustainability and safety, based on the PROMETHÉE 11 method. The adoption of this model provides more confidence and visibility for decision makers. One of the differentiators of this model is the use of a fragmented set of improvement alternatives. These alternatives were combined with some restrictions to create a global set of alternatives. An application to three scenarios, considering realistic data, was developed. The results of the application show that the model should be incorporated into the strategic planning process of organizations.
\end{abstract}

Keywords

Quality management. Multicriteria decision analysis. Civil construction.

\section{Introduction}

Continuous improvement of enterprise processes may be a key issue in contributing for its business excellence. Therefore, improving processes quality is a powerful choice for advancing in competition, with market and cost advantages.

Civil construction, the focus of this study, is composed of a series of activities with different degrees of complexity. These activities are interconnected by a wide product diversification with various technological processes and different types of demand (MELLO; AMORIM, 2009). To select some of the improvement alternatives (programs, methods or standards), the decision maker of the construction company has several axes of evaluation (criteria). These criteria of evaluation are elements that drive the analysis, and they should be established based on modeling of consequences, so that they represent relevant dimensions of the problem as it has been shown in many studies in the literature (VINCKE, 1992;
TSAI; HSU; CHOU, 2011; BRITO; ALMEIDA, MOTA, 2010; POLITIS; SISKOS, 2010; MORAIS; ALMEIDA, 2006; MOTA; ALMEIDA; ALENCAR, 2009; VALOIS; ALMEIDA, 2009; ALMEIDA; DUARTE, 2011; MORAIS; CAVALCANTE; ALMEIDA, 2010).

The need for multi-criteria evaluation in order to establish a support structure for decision-making is then set. The objective of this research work is to develop a model that facilitates the selection and sequencing of implementation of improvement alternatives directed to Quality, Safety, Sustainability and Rationalization in construction companies. A data survey of four construction companies established in the metropolitan area of Recife in Brazil was performed. The interview was partially used, and the points of interest discussed were: identification of improvement practices undertaken in the sector, criteria for selection of improvement alternatives, importance and understanding of them. 
Therefore, a modeling approach was performed using the Multicriteria Decision method: PROMETHEE 11. The application of this method was conducted based on interviews conducted in construction companies and three scenarios were developed to analyze the problem. The application required the use of a fragmented set of improvement alternatives, which have been combined with some restrictions to become a global set of alternatives. Following criteria are considered: impact of the benefits on the production process, positive impact on the company's image, average cost of implementation and average length of implementation.

\section{Multi-criteria decision aid}

Multi-criteria decision methods address specific situations in which a decision maker has to solve one problem dealing with several objectives to be achieved simultaneously (TSAI; HSU; CHOU, 2011; BRITO; ALMEIDA; MOTA, 2010; POLITIS; SISKOS, 2010; MORAIS; ALMEIDA, 2006; MOTA; ALMEIDA; ALENCAR, 2009; VALOIS; ALMEIDA, 2009; ALMEIDA; DUARTE, 2011; MORAIS; CAVALCANTE; ALMEIDA, 2010).

The families of approaches to methods of decision support can be classified into three major groups according to Vincke (1992):

a) Synthesis Function or Multiple Attribute Utility Theory (MAUT), which brings together different points of view in a single function that should be subsequently optimized (the American School). Examples of models thus considered are: MAUT, AHP, SMART;

b) Outranking Methods (the French School), which include the construction of outranking relations, which represent the decision makers's set of preferences. These methods seek to explore relations in a way that helps the decision maker to solve the problem. They differ from the American School mainly by allowing for the possibility of incomparability between alternatives. Examples of such models are: ELECTRE; PROMETHEE; QUALIFLEX; OROEST; MELCHIOR;

c) Interactive methods are, in general, a sequence of dialog steps and calculations, through which a systematic exploration of space making is made. Examples of such models are: STEM; TRIMAP. Note that interactive methods are not addressed in this article. PROMETHEE II, focus of the work, took the non-compensatory hypothesis, which tends to favour more balanced alternatives (alternatives that have reasonably good ratings in all criteria) and provides a cardinal score for each alternative that can be used to develop a pre - complete order.

It is worth to point out that MCDM methods have been supported for many tools, according to patents records, associated with a variety of themes such as: Business Process Management (CAMPOS; DAHER; ALMEIDA, 2011) and Group Decision Support (DAHER; ALMEIDA, 2010).

There are few applications of Multiple-criteria decision-making (MCDM) in total quality management (TQM) context problems in the literature, for instance: a multi-criteria evaluation model to evaluate the expected service quality is proposed within the airport passenger service context (TSAl; HSU; CHOU, 2011), selecting technologies that will support the aims of strategic total quality management (MADU et al., 1996); ranking of critical factors for TQM implementation in Shanghai manufacturing industry (CHIN, 2002); a systematic decision process for selecting external consultant in TQM program (SAREMI; MOUSAVI; SANAYEl, 2008); Selection of lean manufacturing systems (GURUMURTHY; KODALl, 2008), Selecting improvement initiatives and quality management (QM) approaches in three companies in Thailand (THAWESAENGSKULTHAl, 2010) and Quality Function Deployment (QFD) combined with decision support system (ANDRONIKIDIS et al., 2009; BEHZADIAN et al., 2013; KAVOSI; MOZAFFARI; MAVI, 2011).

It is important to mention that this study is aimed at aligning MCDM and quality management based on civil construction, concerning which publications are scarce.

\subsection{Preference method for enrichment evaluation (Promethee)}

The family of PROMETHEE methods aims to build a relationship of Outranking, This family adds information between the alternatives and the criteria, and uses this relationship to support the decision. In PROMETHEE, the decision maker's preference in favor of one alternative a over another option $b$ increases with a greater difference $\left[f_{j}(a)-f_{j}(b)\right]$ between the performance of the alternatives for each criterion $j$ and $f_{j}(a)$ and $f_{j}(b)$, respectively, are the values of the performance of the alternatives $a$ and $b$ in criterion $j$.

Brans and Vincke (1985) presented six different ways to determine such a preference, which have values between 0 and 1 from the definition of the general functions, or preferably according to Table 1 .

Depending on the general criteria set for the criterion $\mathrm{j}$, the decision maker may be required to define the parameters $q_{j}, p_{j}$ and $s_{j}$. These parameters have the following meanings, according to Brans and Mareschal (1992):

- Indifference Threshold $\left(q_{\mathrm{j}}\right)$ : this represents the biggest difference between $f_{j}(a)$ and $f_{j}(b)$ below which the decision maker considers that $\mathrm{a}$ and $\mathrm{b}$ are indifferent; 
Table 1. PROMETHEE preference functions.

\begin{tabular}{|c|c|c|}
\hline $\begin{array}{l}\text { Type } 1 \text { - Usual Criterion } \\
\text { No Threshold }\end{array}$ & $\begin{array}{l}f f(a)-f f(b)>0 \\
f j(a)-f f(b) \leq 0\end{array}$ & $\begin{array}{l}F(a, b)=1 \\
F(a, b)=0\end{array}$ \\
\hline $\begin{array}{l}\text { Type 11-U-Shape Criterion } \\
\text { q threshold }\end{array}$ & $\begin{array}{l}f j(a)-f j(b)>q \\
f j(a)-f j(b) \leq q\end{array}$ & $\begin{array}{l}F(a, b)=1 \\
F(a, b)=0\end{array}$ \\
\hline $\begin{array}{l}\text { Type 111- U-shape Criterion } \\
\text { p threshold }\end{array}$ & $\begin{array}{l}f f(a)-f j(b)>p \\
f j(a)-f j(b) \leq p \\
f j(a)-f j(b) \leq 0\end{array}$ & $\begin{array}{l}F(a, b)=1 \\
F(a, b)=f j(\mathrm{a})-f j(\mathrm{~b}) / \mathrm{p} \\
F(a, b)=0\end{array}$ \\
\hline $\begin{array}{l}\text { Type IV- Level Criterion } \\
q \text { and } p \text { thresholds }\end{array}$ & $\begin{array}{l}/ f j(a)-f(j(b) />p \\
q</ f j(a)-f j(b) / \leq p \\
/ f j(a)-f j(b) / \leq q\end{array}$ & $\begin{array}{l}F(a, b)=1 \\
F(a, b)=1 / 2 \\
F(a, b)=0\end{array}$ \\
\hline $\begin{array}{l}\text { Type V- Linear Criterion } \\
q \text { and } p \text { thresholds }\end{array}$ & $\begin{array}{l}f f(a)-f(b)>p \\
q<f(a)-f(b) \leq p \\
f j(a)-f j(b) \leq q\end{array}$ & $\begin{array}{l}F(a, b)=1 \\
F(a, b)=(/ f j(a)-f j(b) /-q) /(p-q) \\
F(a, b)=0\end{array}$ \\
\hline $\begin{array}{l}\text { Type Vl - Gaussian Criterion } \\
\text { s thresholds }\end{array}$ & $\begin{array}{l}f j(a)-f(b)>0 \\
f f(a)-f_{j}(b) \leq 0\end{array}$ & $F(a, b)=0$ \\
\hline
\end{tabular}

Source: Adapted from Brans and Vincke (1985).

- Preference Threshold $\left(p_{\mathrm{j}}\right)$ : this is the smallest value of this difference over which the decision maker expresses a strict preference in favor of a stock;

- Threshold $\left(s_{\mathrm{j}}\right)$ : this corresponds to an average degree of preference and is between a threshold of preference $q$ and a threshold of strict preference $p$.

Comparing the alternatives a and $\mathrm{b}$, the degree of outranking $\pi(a, b)$ is, according Vincke (1992):

$\pi(a, b)=\frac{1}{P} \sum_{j=1}^{n} p_{j} F_{j}(a, b)$

as:

$P=\sum_{j=1}^{n} p_{j}$

Then, the alternatives are ordered as follows:

- Descending order of $\phi+(a)$, where $\phi+(a)=\pi \Sigma(a, b)$, called the outflow, represents the intensity of preference for $a$ on all alternatives. The higher $\phi+(a)$, the better the alternative;

- Ascending order of $\phi-(a)$, where: $\phi-(a)=\pi \Sigma(b, a)$, called the inflow. It represents the intensity of preference for all other alternatives on a. The smaller $\phi-(a)$, the better the alternative.

The PROMETHEE family of methods includes following methods (BRANS; VINCKE, 1985; BRANS; MARESCHAL, 1992; TALEB; MARESCHAL ,1995):

- PROMETHEE 1 - the intersection between previous flows establishes an Outranking relationship between alternatives, taking incomparability into account, establishing a incomplete pre-order among the alternatives;

- PROMETHEE 11 - ranks the alternatives, establishing an order of $\phi(a)=\phi+(a)-\phi-(a)$ (liquid flow); establishes a complete pre-order among the alternatives;

- PROMETHEE $\mathrm{III}$ and IV - were developed for the treatment of more sophisticated decision problems, particularly with a stochastic component;
- PROMETHEE V - with this implementation, a complete order among the alternatives is established (PROMETHEE 11), restrictions are introduced, and the problem identified for the options selected. This method incorporates a philosophy of integer optimization;

- PROMETHEE VI - when the decision maker is unable or unwilling to define precisely the weights for the criteria, ranges of possible values can be identified rather than a fixed amount for each weight. In these cases, the implementation of PROMETHEE $\mathrm{Vl}$ is recommended.

Each of these methods is appropriate for a particular decision situation. For the study conduct in this paper the PROMETHEE 11 has been found to be the most suitable. That is, the situation requires a ranking, with a complete pre-order among these alternatives.

A comprehensive literature review, including methodologies and applications issues, is given by Behzadian et al. (2010) on PROMETHEE methods. They analyze 217 papers from 100 journal contributions related to PROMETHEE methods, which are categorized into application areas and non-application papers. However, according to their study only seven papers are related to PROMETHEE methods applications considering quality. Most of these papers deal with general problems, including quality criteria, such as: selecting residential houses based on air quality criteria, and determining water quality behavior.

\section{Construction of the model}

The definition of alternatives (solutions, decisions) is sometimes one of the most difficult steps in the process of supporting decision-making (VINCKE, 1992). For this author, the group of $A$ alternatives can be stable or progressive or globalized and fragmented. 
Stable - when the set of $A$ alternatives is defined a priori as finite and not open to changes during the process.

Progressive - can be modified in the process, either because of results that appear during the process, or because the decision problem is, naturally, in a changing environment.

Globalized - each element of the $A$ set excludes some other one.

Fragmented - the results of the decision-making process involve various combinations of elements of $A$.

For construction of the model, a framework of three steps is required: (1) Development of the fragmented set of alternatives. (2) Conversion of the fragmented set into a globalized set and (3) Application of Decision-Making.

Then, to better understand the model, some concepts are developed that will support the construction process. For situations where the set of $A$ alternatives $\mathrm{A}$ is stable and fragmented, there is a need to convert this set to a Globalized one from simple arrangements and simple arrangements without permutation (simple combinations) as per the second stage of the framework. After this conversion, the conditions have been met that enable the decisionmaking process to be applied appropriately, as shown in the third stage.

\subsection{Drawing up the fragmented set of alternatives}

The research is aimed at medium and large companies in the sector of residential, commercial and institutional building and which also work with public works (tenders), in order to encompass a larger number of alternatives for improving processes in the aspects of Quality, Environment and Safety at Work. The model can be used easily by small businesses, including a more simplified set of alternatives for improvements. To Claver and Tarí (2008), several empirical studies have shown the link between quality management practices and improved performance, while others do not find such a link. In general, although studies have focused mainly on large firms, the literature shows that the implementation of quality management may impact on performance in medium-sized enterprises and in large firms.

As a result, eight alternatives were considered for improving the process, that is, improvement alternatives for the production process in the Civil Construction Sector in Brazil.

They are alternatives are subsequently presented with a short description:

- Alternative $1\left(A_{1}\right)$ - Implementation of ISO Standard 9001:2008 and/or Brazilian Program of Quality and Productivity in the Habitat (PBQP-H) / System of
Evaluation of the Compliance of Service Companies and Works (SiAC) - Level A.

Standard with guidelines for improving and controlling the process, with a view to certification and initial level for an efficient Quality Management System. It is worth stressing that Level A of SiAC covers 100\% of 1S0 9001:2008.

Knowledge and application of some activities / methodologies are important for implementing this series of standards, such as 5S, PDCA Cycle and the Traditional Seven Quality Management Tools. According to Sampaio, Saraiva and Rodrigues (2010), it is important to emphasize that some companies that have become certified based mostly upon external motivations, defined their main goal as 'obtaining registration', and thus are of a very limited nature in terms of quality management systems implementation and certification.

- Alternative 2 (A2) - Implementation of the PBQP-H System of Evaluation of the Compliance of Service Companies and Works (SiAC)- Level B;

Standard with guidelines for improving and controlling the process, with a view to certification, and which cover 73.58\% of 1S0 9001:2008;

- Alternative 3 (A3) - Implementation of the PBQP-H System of Evaluation of the Compliance of Service Companies and Works (SiAC)- Level C;

Standard with guidelines for improving and controlling the process, with a view to certification, and which cover $62.26 \%$ of 150 9001:2008;

- Alternative 4(A4)- Implementation of the PBQP-H System of Evaluation of the Compliance of Service Companies and Works (SiAC)- Level D;

Standard with guidelines for improving and controlling the process, with a view to certification, and which cover 26.42\% of 1S0 9001:2008;

- Alternative 5 (A5)- Implementation of the Seven Management Tools for Quality.

These Seven Tools are: Relations Diagram, Affinity Diagram, Tree Diagram, Matrix Diagram, Matrix data analysis, Arrow Diagram, Process Decision Program Chart. These tools give support to planning and to help understand and solve problems.

- Alternative 6 (A6)- Implementation of Standard ISO 14001:2004

Standard with guidelines for improving the process in the aspects related to the environment.

- Alternative 7(A7) - Implementation of Standard OHSAS 18001:2007;

Standard with guidelines for improving the process in the aspects related to Health and Hygiene at Work;

- Alternative 8(A8) - Implementation of Lean Construction. 
Principles of Lean Production targeted on the Civil Construction segment, which encompass stabilizing the flow of material and information (flow kaizen), improving the construction processes (process Kaizen) and just-in-time production.

In this work, the $A$ group of alternatives is considered stable and fragmented, since combinations of the eight alternatives presented will be used.

According to Mast and Bergman (2006), improvement programs teach people a scientific attitude towards problem solving and quality and efficiency improvement. In the study by Oliveira et al. (2011), the authors ratify the importance of the use of quality tools and programs because these options, when adopted, generate considerable competitive advantages. The eight alternatives presented aim at improving the production process, the work environment and satisfying the end customer, collaborators and society. However, simultaneous implementation of some alternatives is considered more difficult in this context because there is some resistance to changes at all levels of the hierarchy, due to a strongly ingrained organizational culture. The construction sector is a very traditional one, in which innovations occur somewhat more slowly.

The initial implementations of the same ISO 9000, ISO 14000 and OHSAS 18000 are more complex and are utilized less in the construction industry in Brazil. Thus, in the case of this work, the implementations of these standards will be considered in isolation.

A construction company can also choose to implement a Quality Management System based on the 1SO 9001:2008 (ASSOCIAÇÃO..., 2008) standard between levels A (100\% of the standard), B (73.58\%), C (62.26\%) or D (26,42\%) of the SiAC in accordance with the Brazilian Program for Quality and Productivity (2012) in the Habitat (PBQP-H in Portuguese). This program has fostered raising the quality and productivity of the various agents of construction. As for the seven new tools of quality planning that characterize alternative 7 , they can be implemented, whether simultaneously or not, with the other alternatives.

Programs such as Rationalization in Civil Construction, a product of the COMPETIR project, resulting from the Technical Cooperation Agreement between the governments of Brazil and Germany, may be slotted into Alternative $8\left(A_{8}\right)$.

\subsection{Conversion of the fragmented set into a globalized one}

The new alternatives for the implementation of choice will be obtained through simple combinations of the 8 alternatives presented.
The new alternative from this globalized set will be deemed a Macro Alternative (MA). The purpose of this designation is only to differentiate the 8 improvement alternatives from the new alternatives obtained by the combinations. In this context, some observations are considered, such as:

- The alternatives $A_{1}, A_{2}, A_{3}$ and $A_{4}$ are considered mutually exclusive, i.e. they cannot be combined with each other;

- The macro alternative that might contain $A_{1}$ (ISO 9001:2008/SiAC level A), for example, may not contain $A_{2}$ (SiAC level B), $A_{3}$ (SiAC level C) or $A_{4}$ (SiAC level D), since $A_{1}$ already includes all D, C and B levels.

It is worth noting that the permutation $\left(P_{n=} n\right.$ !) will not be brought about, since the groupings are chosen from elements / alternatives that differ from each other only by the nature of their elements and not by their ranking. The simple combinations were obtained as per equation (3).

$\mathrm{p} ! \mathrm{C}_{\mathrm{n}, \mathrm{p}}=\mathrm{A}_{\mathrm{n}, \mathrm{p}} \rightarrow \mathrm{C}_{\mathrm{n}, \mathrm{p}}=\mathrm{A}_{\mathrm{n}, \mathrm{p}} / \mathrm{p} !=\mathrm{n} ! /(\mathrm{p} !(\mathrm{n}-\mathrm{p}) !)$

$C=$ simple Combination

$A=$ simple Arrangement

The following topics introduce important observations in order to dimension the total set of macro alternatives

1) When the improvement alternative $A_{1}$ is considered, there is the group $A_{1}, A_{5}, A_{6}, A_{7}, A_{8}$, which can be grouped 2 by 2,3 by 3,4 by 4 and 5 by 5 to form the macro alternatives;

2) When the improvement alternative $A_{2}$ is considered, there is the group $A_{2} A_{5}, A_{6}, A_{7}, A_{8}$ which can be grouped 2 by 2,3 by 3,4 by 4 and 5 by 5 to form the macro alternatives;

3) When the improvement alternative $A_{3}$ is considered, there is the group $A_{3}, A_{5}, A_{6}, A_{7}, A_{8}$ which can be grouped 2 by 2,3 by3, 4 by 4 and 5 by 5 to form the macro alternatives;

4) When the improvement alternative $A_{4}$ is considered, there is the group $A_{4} A_{5}, A_{6}, A_{7} A_{8}$ which can be grouped 2 by 2,3 by 3,4 by 4 and 5 by 5 to form the macro alternatives.

The improvement alternatives were combined to dimension the macro alternatives. Thus it was considered that the construction company established a globalized set of 79 macro alternatives.

\subsection{Framework for the decision making process}

Among the global set of alternatives drawn up based on the combinations, the construction company 
will select a macro alternative for improvement in order to achieve its strategic objectives in the medium and long term. In order to structure the sequencing of implementation, a ranking will be performed to identify, for example, if OHSAS 18000 will be applied before or after the series of ISO 14000 standards, and by doing so, the problematic of ranking is identified.

The purpose of the Global Plan of Action is to select the macro alternative for improvement to be adopted. Thereafter, if the macro alternative includes more than one improvement alternative, they will be ranked with a view to sequencing the activities and drawing up a detailed work plan with its schedule, in an effective way according to Figure 1.

\section{- Description of the Systematics of Selection}

The procedure for selecting the macro alternative of the process comprises the steps presented below.

\section{- Identification of Strategic Objectives}

First of all, the construction company's long-and medium-term strategic objectives are identified in the strategic plan already drawn up by the company, or through brainstorming sessions with senior management and key people in the organization, should the company not have a formalized plan.

According to Schwarber (2005), this starts with objectives, with the group asking itself: What are we trying to accomplish? What are the results we are trying to achieve? This paves the way for honest, open discussion and eliminates jumping to alternatives.

\section{- A Meeting to establish the criteria}

Thereafter, a meeting is held with the stakeholders to define the criteria to be used, such as, for example: cost of implementation; length of implementation; time of adoption as culture and ease of implementation.

The actors involved in this meeting include decision-makers (directors, shareholders or key people in the organization), the facilitator and analyst.

\section{- Presentation of the Macro Alternative}

In this step, the presentation and subsequent clarification by the analyst with regard to the 79 macro alternatives for improvement of the process applied in the civil construction industry are made to the decision maker.

\section{- Choice of Multicriteria Method}

The multicriteria method is chosen by the analyst based on an analysis of various factors such as: type of problem, scenario under study, understanding of the decision-making process by the decision maker, the actors, the preference structure, and so on.

- Choice of the macro alternative to be implemented

In this stage, the application of the multicriteria model for the selection of the macro alternative is conducted. As a result, the construction company will

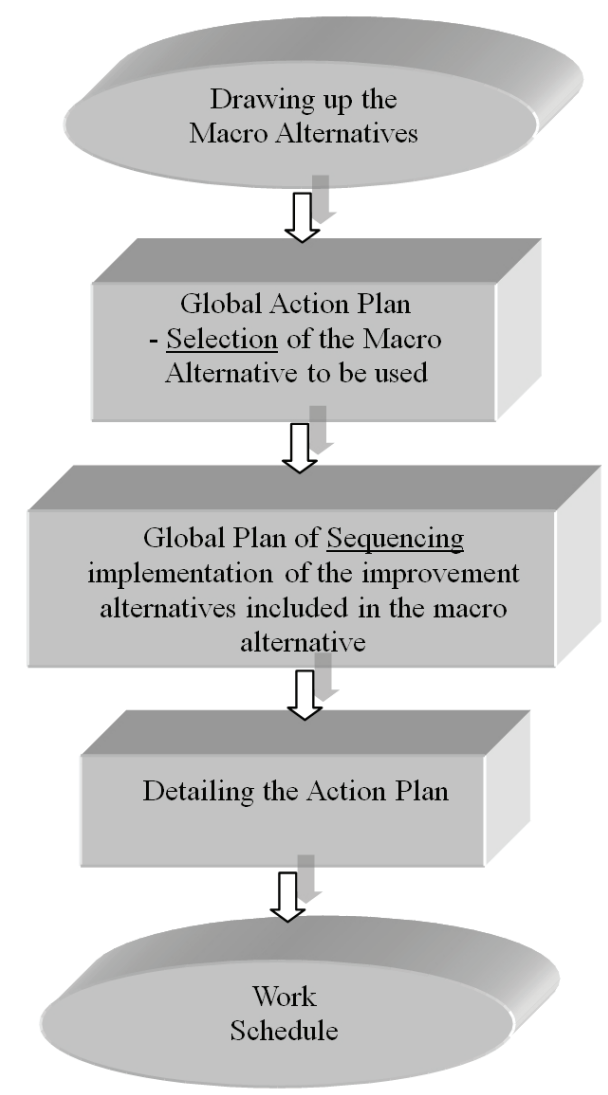

Figure 1. Framework of the Decision Making Process.

have a macro alternative which comprises between one and five improvement alternatives.

\section{- Description of the Systematics of Ranking}

The procedure for ranking the improvement alternatives included in the macro alternative for improvement of the process comprises the steps presented below:

\section{- Presentation of the macro alternative chosen}

The macro alternative chosen will be presented to the construction company. If it includes more than one improvement alternative, ranking will be required.

\section{- Choice of Method}

If the method chosen earlier in the systematics of selecting the alternative includes ranking the macro alternative, this step of choosing a new multicriteria method is unnecessary, since there is ranking of all the macro alternatives.

In some selection/choice methods such as Electre 1, for example, the $P \alpha$ problematic is clarified by way of choosing a subset that is restricted as much as possible and contains the best alternatives, i.e. a subset $\mathrm{K}$ (minimum dominant set). Thus, there will be a need to use another method for the systematics 
of ranking the improvement alternatives contained in the macro alternative.

\section{- Sequencing of Implementation}

In this step, the aim is to sequence the improvement alternatives presented in the macro alternative. It is worth stressing that one should not be forced to use a method that supplies the ranking of macro alternatives in the systematics of choice / selection in order to take advantage of the results obtained.

When there is no need to use a new method to rank the improvement alternatives contained in the macro alternative, this is because the results from the selection model already applied will be used.

In this case, the result from the model selecting the macro alternative displays a ranking of all the macro alternatives contained in this model, including those containing only one improvement alternative.

Thus, there is a need to know the ranking of the improvement alternatives contained in the macro alternative, as per the illustrative example below.

\section{- Illustrative example}

Macro Alternative 36 results from the systematics of selection, as shown below.

Macro Alternative 36 $\mathrm{A}_{2}, \mathrm{~A}_{5}$ and $\mathrm{A}$

There will be a need to conduct the sequencing of the alternatives $A_{2}, A_{5}$ and $A_{7}$, Therefore, the ranking of the macro alternatives 2,5 and $\mathbf{7}$ is verified in the result from the selection model. Respectively, they include only the improvement alternatives $A_{2,} A_{5}$, and $\mathrm{A}_{7}$, as shown below.

\begin{tabular}{|c|c|}
\hline Macro Alternative 2 & $\mathrm{A}_{2}$ \\
\hline Macro Alternative 5 & $\mathrm{A}_{5}$ \\
\hline Macro Alternative 7 & $\mathrm{A}_{7}$ \\
\hline
\end{tabular}

If the company has the result which is the sequencing of the improvement alternatives, it will be able to target its resources more efficiently and effectively, thus reducing costs and increasing its competitive advantage in the market.

\section{- Detailing the Action Plan}

This step takes time and effort, and it is where many points which cause the greatest difficulties when implementing a management system, program or methodology in a construction company are thought through in advance. They are: organizational culture and resistance to change; excessive bureaucracy; lack of staff involvement; lack of commitment from top management; and so forth.

Many research results have shown that one of the main reasons for failure in implementing quality management or other advantageous managerial frameworks is insufficient understanding and involvement of employees, and insufficient involvement and leadership of top management (DAHLGAARD PARK; DAHLGAARD, 2010;
LAOHAVICHIEN; FREDENDALL; CANTRELL ,2010; VALMOHAMMADI, 2011; CORREDOR; GOÑI, 2011; HERAS-SAIZARBITORIA, 2011).

\subsection{Criteria}

Vincke (1992) defines a criterion as a function $\mathrm{g}$, defined on $A$, taking its values in a totally ordered set, and representing the decision-maker's preferences according to some point of view.

An overall analysis was performed in 4 construction companies in the Metropolitan Region of Recife in Brazil in order to obtain a preliminary view and better understanding of the criteria. Using partially structured interviews, a convergence to 4 important criteria was verified: implementation cost, length of implementation, positive impact on the corporate image and impact of the benefits on the production process.

It is noteworthy that measurements of the importance of criteria such as weights or other parameters should be determined within the axiomatic structure of each method and can vary in meaning from one method to another. Another point to stress is that the criteria used may change in accordance with the company or even for the same company after a certain period of time.

\section{Application of the PROMETHEE 11 Method}

The applications shown below are not a real specific case, but they consider realistic data, based on a given context and structure of relationship between the variables considered.

Three scenarios were developed to analyze the problem, and each scenario corresponds to a specific vector of weight that meets the applied research according to Table 2 .

The criteria may vary according to the situation of the problem, and may be qualitative and quantitative according to Table 3.

- Impact of the benefits on the production process $\left(\mathrm{C}_{1}\right)$ : it is also a qualitative criterion and the preference function Type 1 (Usual Criterion - no Threshold) was adopted;

- Positive impact on the company's image $\left(C_{2}\right)$ : it is also a qualitative criterion and the preference function Type 1 (Usual Criterion - no Threshold) was adopted;

- Average cost of implementation $\left(C_{3}\right)$ : preference function Type 11 (Shape Criterion- q threshold) was considered more appropriate, as it uses the Indifference Threshold. The construction company will remain indifferent to certain differences between the costs. It is a criterion for minimization; 
Table 2. Scenarios.

\begin{tabular}{lcccc}
\hline \multirow{2}{*}{ Weight } & \multicolumn{4}{c}{ Criteria } \\
\cline { 2 - 5 } & $\begin{array}{c}\text { Impact of the benefits on } \\
\text { the production process }\left(C_{1}\right):\end{array}$ & $\begin{array}{c}\text { Positive impact on the } \\
\text { company's image }\left(C_{2}\right)\end{array}$ & $\begin{array}{c}\text { Average cost of } \\
\text { implementation }\left(C_{3}\right)\end{array}$ & $\begin{array}{c}\text { Average length of } \\
\text { implementation }\left(C_{4}\right):\end{array}$ \\
\hline 1st Scenario & 0,35 & 0,205 & 0,245 & 0,2 \\
2nd Scenario & 0,35 & 0,3 & 0,2 & 0,15 \\
3rd Scenario & 0,4 & 0,3 & 0,2 & 0,1 \\
\hline
\end{tabular}

Table 3. Preference function and criteria characteristics.

\begin{tabular}{|c|c|c|c|c|}
\hline \multirow[b]{2}{*}{ Characteristics } & \multicolumn{4}{|c|}{ Criteria } \\
\hline & $\begin{array}{l}\text { Impact of the benefits on } \\
\text { the production process } \\
\qquad\left(C_{1}\right) \text { : }\end{array}$ & $\begin{array}{l}\text { Positive impact on } \\
\text { the company's image } \\
\qquad\left(C_{2}\right)\end{array}$ & $\begin{array}{c}\text { Average cost of } \\
\text { implementation }\left(C_{3}\right) R \$ 000 \text { 's } \\
\text {-Brazilian currency) }\end{array}$ & $\begin{array}{l}\text { Average length of } \\
\text { implementation }\left(C_{4}\right) \\
\text { (months) }\end{array}$ \\
\hline Max/Min & Max & Max & Min & Min \\
\hline Preference Function & Type 1 & Type 1 & Type 11 & Type 11 \\
\hline Indifference Threshold (q) & --- & --- & 3 & 0,5 \\
\hline Preference Threshold ( $p$ ) & --- & --- & --- & --- \\
\hline Threshold (s) & --- & --- & --- & --- \\
\hline
\end{tabular}

- Average length of implementation $\left(\mathrm{C}_{4}\right)$ : the preference function Type 11 (Shape Criterion - q threshold) was also proposed and it is a criterion for minimization.

The data and parameters were estimated through a literature review and consultation with specialists. Once all parameters have been defined and the array of performance achieved, the process of multicriteria aggregation of preferences begins. In this process, the degree of over-classification of the alternatives, the inflow, outflow, and finally, the liquid flow are determined. At the end, the alternatives are sorted according to their liquid flow.

Table 4 shows the ranking of alternatives according to the liquid flow for the three scenarios.

By applying this method, the following points were recorded:

- For scenario 1, the recommendation was the macro alternative MA 9. It consists of the improvement alternatives $A_{1}$ and $A_{5}$.

This macro alternative is preferable to other options because it results in a greater liquid flow. It is important to mention that the results differ from that of Scenarios 2 and 3. For Scenario 1, MA 9 obtained good performance in the criteria $\mathrm{C} 3$ and $\mathrm{C} 4$ with weights of 0.245 and 0.2 respectively.

- For scenarios 2 and 3, the recommendation was the alternative MA 76. It consists of the improvement alternatives $A_{1}, A_{5}, A_{6}, A_{7}$ and $A_{8}$ This macro alternative is preferable to other options because it has a greater liquid flow result in these two scenarios and it performed well on criteria $\mathrm{C} 1$ and $\mathrm{C} 2$, whose weights are higher when compared to the weights in scenario 1.

\subsection{Systematic of ranking of improvement alternatives}

- Prioritization of improvement alternatives contained in the Macro Alternative 9 (Scenario 1);
Table 4. Ranking of alternatives for the three scenarios.

\begin{tabular}{|c|c|c|c|}
\hline & scenario 1 & scenario 2 & scenario 3 \\
\hline & \multicolumn{3}{|c|}{ Ranking } \\
\hline 1 & MA 9 & MA 76 & MA 76 \\
\hline 2 & MA 39 & MA 78 & MA 78 \\
\hline 3 & MA 65 & MA 63 & MA 77 \\
\hline 4 & MA 64 & MA 77 & MA 63 \\
\hline 5 & MA 41 & MA 64 & MA 79 \\
\hline 6 & MA 66 & MA 72 & MA 72 \\
\hline 7 & MA 31 & MA 79 & MA 59 \\
\hline 8 & MA 63 & MA 59 & MA 64 \\
\hline 9 & MA 74 & MA 67 & MA 68 \\
\hline ......................... & ...................... & ..................... & ..................... \\
\hline 77 & MA 28 & MA 7 & MA 3 \\
\hline 78 & MA 14 & MA 2 & MA 2 \\
\hline 79 & MA 18 & MA 4 & MA 4 \\
\hline
\end{tabular}

After the choice of macro alternative, there is the need to rank the improvement alternatives. In this they are: $A_{1}$ and $A_{5}$. For this ordering, the results of this method are also used. Thus, for this scenario, the options for improvement contained in the MA 9 will be the order of implementation: $A_{5}$ and $A_{1}$, according to Table 5.

- Prioritization of improvement alternatives contained in the Macro Alternative 76 (Scenarios 2 and 3).

For scenarios 2 and 3, the improvement alternatives contained in the MA 76 have this order of implementation: $A_{5}, A_{6}, A_{8}, A_{1}, A_{7}$, as shown on Table 6 below.

\section{Discussion of the results}

Three scenarios were considered. For scenario 1, MA 9 was chosen, consisting of the improvement alternatives $A_{1}$ and $A_{5}$. In this scenario, the criteria $\mathrm{C}_{3}$ and $\mathrm{C}_{4}$ have weights higher than the same criteria in the other two scenarios. As for scenarios 2 and 3, the same alternative was chosen, MA 76. It consists 
Table 5. Ranking of improvement alternatives contained in MA 9.

\begin{tabular}{ccc}
\hline \multicolumn{3}{c}{ Recommendation for scenario 1 - Macro Alternative 9} \\
\hline \multicolumn{3}{c}{ Order of implementation of improvement alternatives } \\
\hline 1st & $A_{5}$ & $\begin{array}{l}\text { Implementation of the Seven Management Tools } \\
\text { for Quality }\end{array}$ \\
2nd & $A_{1}$ & $\begin{array}{l}\text { Implementation of 1SO Standard 9001:2008 and/or } \\
\text { PBQP System of Evaluation of the Compliance of } \\
\text { Service Companies and Works (SiAC)- Level A }\end{array}$ \\
\hline
\end{tabular}

Table 6. Ranking of improvement alternatives contained in MA 76.

\begin{tabular}{|c|c|c|}
\hline \multicolumn{3}{|c|}{ Recommendation for scenarios 2 and 3 - Macro Alternative 76} \\
\hline \multicolumn{3}{|c|}{ Order of implementation of improvement alternatives } \\
\hline $1 \mathrm{st}$ & $A_{5}$ & $\begin{array}{l}\text { Implementation of the Seven Management Tools } \\
\text { for Quality }\end{array}$ \\
\hline 2nd & $A_{6}$ & Implementation of Standard ISO 14001:2004 \\
\hline $3 r d$ & $A_{8}$ & Implementation of Lean Construction \\
\hline 4th & $A_{1}$ & $\begin{array}{l}\text { 1mplementation of 1SO Standard 9001:2008 and/or } \\
\text { PBQP-H System of Evaluation of the Compliance of } \\
\text { Service Companies and Works (SiAC)- Level A }\end{array}$ \\
\hline 5th & $A_{7}$ & Implementation of Standard OHSAS 18001:2007 \\
\hline
\end{tabular}

of the improvement alternatives $A_{5}, A_{6}, A_{8}, A_{1}, A_{7}$. These two scenarios have only minor differences in the weights of the criteria $C_{1}$ and $C_{4}$.

In relation to ordering / prioritizing, the improvement alternative A5 (Implementation of the Seven Quality Management Tools) came in 1st place in MA 9 (scenario 1) and in MA 76 (scenario 2 and scenario 3). The ordering of the alternatives contained in the improvement of MA 76 was the same for both scenarios 2 and 3.

It can be verified that the process of selection and ranking of improvement alternatives for construction companies has an important role in organizational success. The well-planned choice of improvement alternatives with the support of the new method provides several benefits, such as the implementation of improvement changes taking into consideration important dimensions: growth in the production process, corporate image, cost and implementation time.

\section{Final considerations}

When an organization shows concern for Quality Management, Environment and Safety, the production process is benefited in some way, such as reduction of defects, rework or waste, as well as the reduction / elimination of occupational accidents and increased organization and comfort in the environment of these workers. The improvement possibilities (alternatives) of the production process involve these three areas.

One of the differentials of this model is the use of a fragmented set of improvement alternatives. These alternatives were combined with some restrictions so that they became a new global set of alternatives (macro alternatives). The model of this study is particularly aimed at medium and large construction companies. It may be noted that, in the modeling, there were no financial constraints regarding the maximum number of improvement alternatives, but these restrictions can be taken into consideration, especially for smaller companies. Thus, this model can also be adapted for small businesses, with different alternatives or a further reduced fragmented set.

The measurement of each criterion worked on in the model demands detailed analysis. Another point to be made carefully is the correct measurement of each criterion for each macro alternative, this being an alternative that often works with combinations of improvement alternatives, and these combinations are not always linear functions. Therefore, the proposed model helps the selection and ranking of improvement alternatives of the process and it has an important role in organizational strategy. It should be inserted in the strategic planning process.

\section{References}

ALMEIDA, A. T.; DUARTE, M. D. 0. A multi-criteria decision model for selecting project portfolio with consideration being given to a new concept for synergies. Pesquisa Operacional, v. 32, p. 1-18, 2011.

ANDRONIKIDIS, A. et al. The application of quality function deployment in service quality management. The TQM Journal, v. 21, n. 4, p. 319-333, 2009. http://dx.doi. org/10.1108/17542730910965047

ASSOCIAÇÃO BRASILEIRA DE NORMAS TÉCNICAS - ABNT. NBR ISO 9001:2008: Sistemas de gestão da qualidade Requisitos. ABNT, 2008.

BEHZADIAN, M. et al. PROMETHEE: A comprehensive literature review on methodologies and applications. European Journal of Operational Research, v. 200, p. 198215, 2010. http://dx.doi.org/10.1016/j.ejor.2009.01.021

BEHZADIAN, M. et al. PROMETHEE Group Decision Support System and the House of Quality. Group Decision and Negotiation, v. 22, n. 2, p. 189-205, 2013. http://dx.doi. org/10.1007/s10726-011-9257-3

BRANS, J. P.; VINCKE, P. H. A preference ranking organization method, the PROMETHEE method for MCDM. Management Science, v. 31, p. 647-656, 1985. http://dx.doi.org/10.1287/mnsc.31.6.647

BRANS, J. P.; MARESCHAL, B. Promethee V: MCDM problems with segmentation constraints. INFOR, v. 30, n. 2, p. 85-86, 1992.

BRAZILIAN PROGRAM FOR QUALITY AND PRODUCTIVITY IN THE HABITAT - PBQP-H. Disponivel em: <http://www2. cidades.gov.br/pbqp-h/projetos_siac.php>. Acesso em: 02 fev. 2012.

BRITO, A. J.; ALMEIDA, A. T.; MOTA, C. M. A multicriteria model for risk sorting of natural gas pipelines based on electre tri integrating utility theory. European Journal of 
Operational Research, v. 200, p. 812-821, 2010. http:// dx.doi.org/10.1016/j.ejor.2009.01.016

CAMPOS, A. C. S. M.; DAHER, S. F. D.; ALMEIDA, A. T.; New Patents on Business Process Management Information Systems and Decision Support. Recent Patents on Computer Science, v. 4, p. 91-97, 2011. http://dx.doi. org/10.2174/2213275911104020091

CHIN, K. S. et al. An AHP based study of critical factors for TQM implementation in Shanghai manufacturing industries. Technovation, p. 707-715, 2002. http:// dx.doi.org/10.1016/S0166-4972(01)00065-7

CLAVER, E.; TARI, J. J. The Individual Effects of Total Quality Management on Customers, People and Society Results and Quality Performance in SMEs. Quality and Reliability engineering International, v. 24, p. 199-211, 2008. http://dx.doi.org/10.1002/qre.885

CORREDOR, P.; GOÑI, S. TQM and performance: is the relationship so obvious? Journal of Business Research, v. 64, p. 830-838, 2011. http://dx.doi.org/10.1016/j. jbusres.2010.10.002

DAHER, S. F. D.; ALMEIDA, A. T. Recent Patents Using Group Decision Support Systems: A Short Review. Recent Patents on Computer Science, v. 3, p. 81-90, 2010. http://dx.doi.org/10.2174/2213275911003020081

DAHLGAARD PARK, S.; DAHLGAARD, J. J. Organizational learnability and Innovability: a system for assessing, diagnosing and Improving Innovations. International Journal of Quality and Service Sciences, v. 2, n. 2, p. 153-174, 2010. http://dx.doi. org/10.1108/17566691011057339

GURUMURTHY, A.; KODALl, R. A multi-criteria decisionmaking model for justification of lean manufacturing systems. International Journal of Management Science and Engineering Management, v. 3, n. 2, p. 100$118,2008$.

HERAS-SAIZARBITORIA, 1. Internalization of ISO 9000: an exploratory study. Industrial Management \& Data Systems, v. 111, n. 8, p. 1214-1237, 2011. http://dx.doi. org/10.1108/02635571111170776

KAVOSI, M.; MOZAFFARI, M. M.; MAVI, R. K. Incorporating cost and environmental factors in quality function deployment using TOPSIS method. International Journal of Quality Engineering and Technology, v. 2, n. 1, p. 6374, 2011. http://dx.doi.org/10.1504/1JQET.2011.038723

LAOHAVICHIEN, T.; FREDENDALL, L. D.; CANTRELL, R. S. Leadership and quality management practices in Thailand. International Journal of Operations \& Production Management, v. 31, n. 10, p. 1048-1070, 2010. http:// dx.doi.org/10.1108/01443571111172426

MAST, J.; BERGMAN, M. Hypothesis Generation in Quality Improvement Projects: Approaches for Exploratory Studies. Quality and Reliability engineering International, v. 22, p. $839-850,2006$. http://dx.doi.org/10.1002/ qre.767

MELLO, L. C. B. B.; AMORIM, S. R. L. The subsector of buildings of the civil construction in Brazil: a x-ray of the sector compared to the European Union and the United States Produção, v. 19, n. 2, p. 388-399, 2009.

MORAIS, D. C.; ALMEIDA, A. T. Water supply system decisionmaking using multicriteria analysis. Water $S A$, v. 32, n. 2, p. 229-235, 2006.

MORAIS, D. C.; CAVALCANTE, C. A. V.; ALMEIDA, A. T. Priorização de áreas de controle de perdas em redes de distribuição de água. Pesquisa Operacional, v. 30, n. 1, p. 15-32, 2010.

MOTA, C. M. M.; ALMEIDA, A. T.; ALENCAR, L. H. A multiple criteria decision model for assigning priorities to activities in project management. International Journal of Project Management, v. 27, n. 2, p. 175-181, 2009. http://dx.doi.org/10.1016/j.jproman.2008.08.005

MADU, C. N. et al. Adoption of strategic total quality management philosophies - Multi-criteria decision analysis model. International Journal of Quality \& Reliability Management, v. 13, n. 3, p. 57-72, 1996. http://dx.doi.org/10.1108/02656719610116081

OLIVEIRA, J. A. et al. A study on the use of quality systems, programs and tools in companies of interior of São Paulo State. Produção, v. 21, n. 4, p. 708-723, 2011. http:// dx.doi.org/10.1590/S0103-65132011005000044

POLITIS, Y.; SISKOS, Y. Self-assessment for measuring business excellence: The MUSABE method. Total Quality Management \& Business Excellence, v. 21, n. 11, p. 1063-1083, 2010. http://dx.doi. org/10.1080/14783360902924283

SAMPAIO, P.; SARAIVA, P.; RODRIGUES, A. G. A classification model for prediction of certification motivations. Total Quality Management \& Business Excellence, v. 21, n. 12, p. 1279-1298, 2010. http://dx.doi.org/10.1080/147833 63.2010 .529367

SAREMI, M.; MOUSAVI, F.; SANAYEl, A. TQM consultant selection in SMEs with TOPSIS under fuzzy environment. Expert Systems with Applications, v. 36, n. 2, p. 2742-2749, 2009. http://dx.doi.org/10.1016/j. eswa.2008.01.034

SCHWARBER, P. D. Leaders and the decision-making process. Management Decision, v. 43, n. 7-8, p. 1086-1092, 2005. http://dx.doi.org/10.1108/00251740510610099

TALEB, M. F. A.; MARESCHAL, B. Water resources planning in the Middle East: application of the PROMETHEE V multicriteria method. European Journal of Operational Research, v. 81, p. 500-511, 1995. http://dx.doi. org/10.1016/0377-2217(94)00007-Y

THAWESAENGSKULTHAI, N. An empirical framework for selecting quality management and improvement initiatives. International Journal of Quality \& Reliability Management, v. 27, n. 2, p. 156-172, 2010. http:// dx.doi.org/10.1108/02656711011014285

TSAI, W.; HSU, W.; CHOU, W. A gap analysis model for improving airport service quality. Total Quality Management \& Business Excellence, v. 22, n. 10, p. 1025-1040, 2011. http://dx.doi.org/10.1080/147833 63.2011 .611326

VINCKE, P. Multicriteria decision-aid. Chichester: John Wiley, 1992.

VALMOHAMMADI, C. The impact of TQM implementation on the organizational performance of Iranian manufacturing SMEs. The TQM Journal, v. 23, n. 5, p. 496-509, 2011. http://dx.doi.org/10.1108/17542731111157608

VALOIS, U.; ALMEIDA, A. T. Support model for multicriteria decision to outsource productive activities based on SMARTS method. Produção, v. 19, n. 2, p. 249-260, 2009. http://dx.doi.org/10.1590/S0103-65132009000200003 